\title{
Practical aspects of inhaler use in the management of chronic obstructive pulmonary disease in the primary care setting
}

This article was published in the following Dove Press journal:

International Journal of COPD

24 July 2012

Number of times this article has been viewed

\section{Barbara P Yawn' \\ Gene L Colice ${ }^{2}$ \\ Rick Hodder ${ }^{3 *}$}

'Department of Research, Olmsted Medical Center, Rochester, MN, USA; ${ }^{2}$ Department of Pulmonary, Critical Care, and Respiratory Services, Washington Hospital Center, Washington, DC, USA; ${ }^{3}$ Divisions of Pulmonary and Critical Care, University of Ottawa, Ottawa, Canada

*Professor Rick Hodder has sadly passed away recently
Correspondence: Barbara P Yawn Department of Research, Olmsted Medical Center, 210 Ninth Street SE, Rochester, MN 55904, USA

Tel +I 5072872758

Fax + I 5072872722

Email byawn@olmmed.org
Abstract: Sustained bronchodilation using inhaled medications in moderate to severe chronic obstructive pulmonary disease (COPD) grades 2 and 3 (Global Initiative for Chronic Obstructive Lung Disease guidelines) has been shown to have clinical benefits on long-term symptom control and quality of life, with possible additional benefits on disease progression and longevity. Aggressive diagnosis and treatment of symptomatic COPD is an integral and pivotal part of COPD management, which usually begins with primary care physicians. The current standard of care involves the use of one or more inhaled bronchodilators, and depending on COPD severity and phenotype, inhaled corticosteroids. There is a wide range of inhaler devices available for delivery of inhaled medications, but suboptimal inhaler use is a common problem that can limit the clinical effectiveness of inhaled therapies in the real-world setting. Patients' comorbidities, other physical or mental limitations, and the level of inhaler technique instruction may limit proper inhaler use. This paper presents information that can overcome barriers to proper inhaler use, including issues in device selection, steps in correct technique for various inhaler devices, and suggestions for assessing and monitoring inhaler techniques. Ensuring proper inhaler technique can maximize drug effectiveness and aid clinical management at all grades of COPD.

Keywords: COPD, inhaler technique, bronchodilator, clinical management

\section{Background}

Chronic obstructive pulmonary disease (COPD) is a preventable and treatable disease that is the third-leading cause of death in the United States. ${ }^{1}$ However, much can be done to improve significantly the quality, and perhaps, duration of life for people with COPD; for instance, modern pharmacotherapy can effectively reduce exacerbations, avoiding morbidity and costly hospitalization. ${ }^{2-7}$ There are also encouraging trends to suggest that pharmacotherapy might have an impact on reducing both the rate of forced expiratory volume in 1 second $\left(\mathrm{FEV}_{1}\right)$ decline and the risk of earlier mortality. ${ }^{3-8}$ Nonpharmacologic therapy, such as collaborative self-management education ${ }^{9,10}$ and pulmonary rehabilitation, ${ }^{11}$ is equally important for COPD management, often enhancing pharmacotherapy approaches.

Primary care physicians make most initial COPD diagnoses based on symptoms of dyspnea and cough in adults aged 40 years and older with a smoking history. Clinical diagnosis requires spirometry confirmation of airflow obstruction. ${ }^{12,13}$ Treatment is then begun and tailored to a patient's needs based on the latest COPD guidelines. ${ }^{14,15}$ The Global Initiative for Chronic Obstructive Lung Disease (GOLD) guidelines clearly state that the choice of inhaler device should depend upon drug availability, cost, the preference of the prescribing physician, and the skills and abilities of the patient. ${ }^{15,16}$ 
The management of COPD is often not optimal, and poor inhaler technique is one of the prime reasons for this. ${ }^{17-19}$ Physicians frequently prescribe inhaler devices based on available/preferred drugs, without considering whether the patient can effectively use them. ${ }^{20}$ Most COPD occurs in older adults who may have comorbid conditions, such as tremor, poor eyesight, arthritis, and cognitive problems that may aggravate effective inhaler device use. Therefore, device selection must be based on COPD severity and the patient's physical and cognitive abilities, as well as insurer and provider tiering, requests for prior authorization, and patient cost-saving requests.

Pharmacologic treatment can provide symptom relief, improve health status, improve exercise capacity, and reduce the frequency and severity of COPD exacerbations. ${ }^{15}$

Table I Inhaled medications available to accomplish goals of COPD therapy in the United States, 2010

\begin{tabular}{|c|c|}
\hline $\begin{array}{l}\text { Goal of COPD } \\
\text { therapy }\end{array}$ & Available inhaled medications \\
\hline $\begin{array}{l}\text { Relief of } \\
\text { breathlessness }{ }^{14,15}\end{array}$ & $\begin{array}{l}\text { - Short-acting } \beta 2 \text {-adrenergic bronchodilators } \\
\text { - Short-acting anticholinergic bronchodilators } \\
\text { - Long-acting } \beta 2 \text {-adrenergic bronchodilators } \\
\text { - Long-acting anticholinergic bronchodilators }\end{array}$ \\
\hline $\begin{array}{l}\text { Improved quality } \\
\text { of life }, 3,7,8\end{array}$ & $\begin{array}{l}\text { - Long-acting } \beta 2 \text {-adrenergic bronchodilators } \\
\text { - Long-acting anticholinergic bronchodilators } \\
\text { - Long-acting } \beta 2 \text {-adrenergic } \\
\text { bronchodilator-ICS combinations } \\
\text { - Long-acting } \beta 2 \text {-adrenergic } \\
\text { bronchodilator-ICS combinations plus long- } \\
\text { acting anticholinergic bronchodilators }\end{array}$ \\
\hline $\begin{array}{l}\text { Improved exercise } \\
\text { capacity }{ }^{14,15}\end{array}$ & $\begin{array}{l}\text { - Short-acting } \beta 2 \text {-adrenergic bronchodilators } \\
\text { - Short-acting anticholinergic bronchodilators } \\
\text { - Long-acting anticholinergic bronchodilators } \\
\text { - Long-acting } \beta 2 \text {-adrenergic bronchodilators } \\
\text { - Long-acting } \beta 2 \text {-adrenergic } \\
\text { bronchodilator-ICS combinations }\end{array}$ \\
\hline $\begin{array}{l}\text { Reduced COPD } \\
\text { exacerbations } s^{14,15}\end{array}$ & $\begin{array}{l}\text { - Long-acting anticholinergic bronchodilators } \\
\text { - Long-acting } \beta 2 \text {-adrenergic bronchodilators } \\
\text { - Long-acting } \beta 2 \text {-adrenergic bronchodilator- } \\
\text { ICS combinations }\end{array}$ \\
\hline $\begin{array}{l}\text { Trend to a reduced } \\
\text { age-related loss } \\
\text { of lung function } \\
\text { 2,3,5,7 }\end{array}$ & $\begin{array}{l}\text { - Long-acting anticholinergic bronchodilators } \\
\text { - Long-acting } \beta 2 \text {-adrenergic } \\
\text { bronchodilator-ICS combinations } \\
\text { - Long-acting } \beta 2 \text {-adrenergic } \\
\text { bronchodilator-ICS combinations plus } \\
\text { long-acting anticholinergic bronchodilators }\end{array}$ \\
\hline $\begin{array}{l}\text { Trend to improved } \\
\text { longevity } 3,5,6\end{array}$ & $\begin{array}{l}\text { - Long-acting anticholinergic bronchodilators } \\
\text { - Long-acting } \beta 2 \text {-adrenergic bronchodilators } \\
\text { alone } \\
\text { - Long-acting } \beta 2 \text {-adrenergic } \\
\text { bronchodilator-ICS combinations }\end{array}$ \\
\hline
\end{tabular}

Abbreviations: COPD, chronic obstructive pulmonary disease; ICS, inhaled corticosteroids.
Table 1 lists the drug combinations for COPD care that are available for inhalation via various devices, including nebulizers, pressurized metered-dose inhalers (pMDIs), and dry-powder inhalers (DPIs).

This review focuses on the practical aspects of inhaler use, including appropriate device selection to best meet an individual patient's needs, ${ }^{21}$ as well as information to facilitate adequate training and monitoring to ensure proper inhaler technique. Key barriers to optimal inhaler use are highlighted, followed by some practical advice to overcome device misuse by the patient with COPD.

\section{Available inhaler devices}

All types of inhaler devices have similar efficacy when tested under strict clinical trial conditions; ${ }^{17,22,23}$ however, in the real-life setting of clinical practice, each inhaler has distinct characteristics that can become advantages or disadvantages for individual patients, affecting clinical outcomes, patient satisfaction, and thus adherence. ${ }^{19,24,25}$ For the individual patient, "inhalers" should not be viewed as equivalent, and device type must become an important variable to consider when planning optimal COPD management. ${ }^{23}$

\section{Pressurized metered-dose inhalers}

The first handheld inhaler was launched by Abbott Laboratories in 1948; however, development of pMDIs in 1955, which are small, portable, and offer quick and reproducible drug delivery, was a big step forward in inhaler design. ${ }^{26}$ There are two types: those that are triggered by a mechanical device (usually a button that should be pushed just after inspiration begins), and those that are breathactuated, which removes the need to coordinate breathing and push the actuator. Limited published evidence exists on the relative benefits of the two types of pMDI. ${ }^{27}$ While inhalation of drugs was a great advance, putting the drugs where they are needed and limiting systemic exposure, the advantages of pMDIs are limited by the need for a specific breathing technique that involves coordination between inspiration and actuation, slow and steady inspiration, and a breath hold. Some of these problems can be overcome by using a pMDI in conjunction with a spacer or holding chamber. Although spacer misuse and failure to properly clean a spacer can decrease drug delivery, ${ }^{28,29}$ use of nonelectrostatic spacers, such as Vortex (PARI Respiratory Equipment, Midlothian, VA) and the AeroChamber Max (Monaghan Medical, Plattsburgh, NY) can overcome this issue. A pMDI is a good inhaler option for many patients 
with COPD; however, inadequate hand-breath coordination, poor fine motor control, hand or finger muscle weakness, or arthritis of the hand can prohibit proper pMDI use. pMDIs with longer drug-delivery periods may reduce some of the impact of poor coordination of efforts. Elderly patients may prefer a breath-actuated pMDI over the usual pMDI, but must have sufficient inspiratory flow (minimum usually considered to be $30 \mathrm{~mL} / \mathrm{second}$ ) to trigger the device.

\section{Dry-powder inhalers}

The DPIs were devised to be easier to operate than pMDIs, ${ }^{22}$ although they require a certain level of peak inspiratory flow (PIF), making them unsuitable for some very infirm or very severe COPD patients. ${ }^{30}$ While in general, many adults find DPIs easier to use than pMDIs, ${ }^{31}$ the different types of DPI (self-contained blister pack device and those requiring capsule insertion), each requiring different techniques, can lead to confusion and ineffective drug delivery. ${ }^{32}$ The selfcontained blister pack device requires opening the device, cocking it, and inhaling. Counters should be checked to ensure the device is not empty. DPIs with dry-powder capsules require removal of the capsule from the individual packets, insertion of the capsule into the device, puncturing the capsule, and inhaling. Dry-powder devices require only a single inhalation.

\section{Nebulizers}

Nebulizers are the oldest form of inhalation device. ${ }^{22}$ Nebulizer use should be limited to patients for whom handheld inhalers are unsuitable, such as those with coordination problems. The devices are generally bulky and inconvenient, expensive, and require regular maintenance and long treatment-delivery times. Use of a nebulizer prolongs drug delivery from seconds to 10-15 minutes. Proper device cleaning is required to prevent bacterial, yeast, or mold contamination.

\section{Soft-mist inhalers}

A new type of handheld inhaler device is the soft-mist inhaler (SMI), which produces a slow-moving, very fine liquid aerosol (a "soft mist"). Because the mist is produced over 1.5 seconds instead of the $<0.5$-second period with most other inhalers, it should allow more flexibility with synchronization between device actuation and inhalation, and therefore may provide greater lower-airway deposition. ${ }^{33}$ Respimat Soft Mist Inhaler (Boehringer Ingelheim, Ingelheim, Germany) is currently available in European, Asian, and South American countries, and will be available in the US in July 2012. ${ }^{34}$

\section{Inhaler device misuse and adherence in the real-world setting}

Several studies have demonstrated that errors in inhaler use are common among patients with COPD $^{35,36}$ (Table 2). One study estimated that while $76 \%$ of pMDI users and $49 \%-55 \%$ of DPI users made at least one error, only $28 \%$ and $11 \%-32 \%$ of pMDI and DPI users, respectively, made errors that compromised the clinical benefits of their medications. ${ }^{35}$ In contrast, a recent study showed that more patients using DPIs made mistakes compared with those using MDIs. ${ }^{18}$ Reasons for poor inhaler use may be divided into a few simple categories: device issues, patient issues, physician and health-care professional issues, practice issues, and cost issues leading to failure to obtain the inhalers. While multiple issues may affect any single patient, we will address the issues individually.

\section{Device issues}

The pMDIs are known to be affected by a variety of problems, including lack of coordination, inadequate breath hold, overly rapid inhalation, and inadequate shaking/mixing (priming) of the inhaler before actuation. ${ }^{37}$ Some devices require upright storage, and priming recommendations are widely variable.

Table 2 Critical inhaler errors

\begin{tabular}{llll}
\hline Critical error & pMDI & $\begin{array}{l}\text { Multidose DPI } \\
\text { Diskus/turbuhaler }\end{array}$ & $\begin{array}{l}\text { Single-dose DPI } \\
\text { HandiHaler/aerolizer }\end{array}$ \\
\hline Failure to remove cap & & $\times$ & $\times$ \\
Holding inhaler upside down & $\times$ & $\times$ & $\times$ \\
Failure to load dose & $\times$ & $\times$ & $\times$ \\
Failure to pierce capsule & & $\times$ & $\times$ \\
Exhaling into device & & $\times$ & $\times$ \\
Failure to make tight seal with lips & & $\times$ & $\times$ \\
Failure to synchronize inhalation with device actuation & $\times$ & $\times$ & \\
Inhalation too weak or too slow & & & $\times$ \\
\hline
\end{tabular}

Abbreviations: DPI, dry powder inhaler; pMDI, pressurized metered-dose inhaler. 
High- and low-temperature extremes such as those found in a car's glove compartment disrupt the delivery system and may inactivate the drug. Most pMDIs are fairly resistant to humidity and can be stored in a bathroom.

Common DPI errors include failure to hold the device upright, exhaling through the mouthpiece, shaking the device, failing to inhale forcefully, and inhaling with an open mouth/failing to maintain a tight seal. ${ }^{38,39}$ DPIs are sensitive to humidity and should not be stored in the bathroom. The capsule packets can be difficult to open, but because of humidity concerns should never be opened and emptied into another container for easier access.

As COPD progresses, the GOLD guidelines recommend the use of multiple classes of inhaled drugs. ${ }^{15}$ In early COPD, all patients should use short-acting inhaled bronchodilators as needed, available by pMDI, DPI, and SMI in various jurisdictions. As the disease progresses, long-acting inhaled bronchodilators are added, requiring the patient to use two inhalers; these inhalers are likely to be of different types, since long-acting bronchodilators are available as pMDIs, DPIs, and SMIs in various jurisdictions. The need for multiple inhalers of different types and different inhaler techniques may confuse patients and impede correct inhaler use. ${ }^{32}$ The automatic substitution of similar long-acting inhaled bronchodilators in DPI format by pharmacists could produce even more confusion, with patients switching from self-contained blister pack DPIs to capsule-based DPIs without proper explanation or education. The different brands of DPI are not simply interchangeable. ${ }^{39,40}$ In severe to very severe COPD (grades 3-4), nebulized medications may also be added to the pMDI and one or more types of DPI or SMI, making therapy regimens complex and confusing.

\section{Patient issues}

Comorbidities, physical and mental capabilities, and inhaler preference or satisfaction will influence the patient's inhalation technique and should affect device selection. Most patients with COPD are long-term smokers and older, meaning they may have a number of comorbidities that can present barriers to effective inhaler use. ${ }^{41}$ Physical issues, such as tremors, poor hand-eye coordination, poor dexterity, arthritis, poor eyesight, poor hearing, or low inspiratory flow rates can impair pMDI, DPI, and SMI use..$^{22,42,43}$

Cognitive and mood disorders can also impair a patient's ability to learn and remember inhalation techniques. ${ }^{22,42}$ Depression is frequent in patients with COPD, ${ }^{44,45}$ and may lead to nonadherence with proper and regular therapy use. ${ }^{46}$ Patients may also have health-literacy or language barriers inhibiting understanding of any inhaler instruction provided. ${ }^{47}$ Patient perceptions about their lung conditions and treatments can also affect treatment adherence (ie, underuse, overuse, and misuse). ${ }^{24,48}$ For example, patients may have negative beliefs that their disease is untreatable, that their physicians cannot help them, or that the treatment will be ineffective or cause side effects. Others save the medications for a time when they will "really need" them and lose the benefit of regular therapy. The level of support through family/caregivers may affect patient enthusiasm for treatment and adherence. Some patients and caregivers may try to cope with the stress of illness by abuse of alcohol or sedatives, which will usually have a negative impact on consistency and success of disease management. ${ }^{49}$

An important variation of improper inhaler use is failure to use the inhaler at all. Patient adherence in COPD is multifactorial and is influenced by the patient, the physician, and society. ${ }^{24,48-50} \mathrm{~A}$ recent study of 11,376 patients with COPD showed that only $52 \%$ used any COPD medications, $40 \%$ discontinued their medication within 30 days, and $70 \%$ discontinued within 90 days. ${ }^{51}$ Nonadherence can be either intentional (patient does not like using the inhaler) or unintentional (patient likes and uses the inhaler, but has poor technique). ${ }^{38,39,52,53}$ Patients may stop using their inhalers if, through poor technique, they are not achieving symptom relief. ${ }^{43,54-56}$ In the Towards a Revolution in COPD Health (TORCH) survival study, good adherence to use of the study drug was found to result in substantially improved outcomes compared with nonadherence, as use of $>80 \%$ of study medication over the 3 years of this trial was associated with significantly lower mortality, and exacerbation and hospitalization rates. Of interest, good adherence to placebo also resulted in significantly lower all-cause mortality. ${ }^{57}$

\section{Physician and health-care professional issues}

Many primary care as well as specialty physicians and nurses lack the awareness, knowledge, and training required to instruct patients in proper inhaler use. ${ }^{58-60}$ In one survey, among health professionals, respiratory therapists were the only group of which $50 \%$ could perform all of the critical steps required for proper inhaler use. ${ }^{36}$ This knowledge gap must be filled. Health professionals must be capable of using multiple educational techniques (eg, verbal, visual, demonstration) to instruct patients, families, and caregivers on why, when, and how inhalers are to be used. Instruction and review must be repeated at each visit to ensure maintenance of proper inhaler technique. Side effects must be 
explained without engendering undue concern. ${ }^{61}$ In primary care, patients are seen multiple times over months or years, and therefore educational messages can be delivered in short segments and repeated as necessary to ensure patient and family understanding. ${ }^{61}$

\section{Practice issues}

Practice systems can also serve as barriers to proper inhaler device selection and technique education. By prohibiting drug-sample use, practices may be left with no devices for patient trials or training. Obtaining placebo devices may overcome this barrier, but requires time and often requests to the pharmaceutical companies manufacturing each of the devices. Busy practices may have little opportunity for interdisciplinary sharing of inhaler technique methods or successful instruction strategies. Having a regularly scheduled annual or biannual inhaler update and review for all clinic employees could improve everyone's ability to teach and ensure correct inhaler use. Sharing responsibility and accountability for inhaler instruction and review can ensure it occurs even when a patient has multiple health concerns to address, as do many patients with COPD. ${ }^{59}$

\section{Cost issues}

Physicians must have information on inhaler costs to share with the patient, including whether a medication has a deductible or co-pay, or the patient must pay the entire cost. Formulary restraints may result in drug substitution by the pharmacist, leaving the patient with a new or unexpected device and no information about its proper use..$^{40}$ Asking pharmacists to always demonstrate inhaler technique may help because not all pharmacists provide this instruction, and simply handing the patient written instructions is often unhelpful. ${ }^{60}$

\section{Practical solutions}

The American College of Chest Physicians and the American College of Asthma, Allergy and Immunology have developed an eight-point checklist to aid in physician selection of inhaler device. ${ }^{17}$ We have distilled the eight points into four practical questions that should be addressed for each patient.

\section{(I) For the chosen drug(s), what devices} are available and what is the fewest number of device types that can be used?

Physicians usually prescribe from a wide variety of medications (Table 1), and inhaler type is often a secondary consideration. Currently, there is a sufficient variety of drug-inhaler combinations to allow selection of desired drugs while attempting to limit the number of different devices required. It is also important to provide sufficient and repeated education about the anticipated benefits of therapy and the likely course of drug use over time. ${ }^{61}$ This information is particularly beneficial to patients who have unrealistic expectations and may stop using their inhaler because of perceived failure of their COPD treatment.

\section{(2) What device is the patient likely to use} properly (given the patient's age and ability)?

It is best to try to match available inhaler devices with the individual patient's ability to use the device effectively. ${ }^{62}$ Caregiver and family expectations, intelligence, reading ability, and emotional stability should also be addressed when assessing inhaler choice. ${ }^{63}$

If the patient has already been prescribed an inhaler, request that he or she demonstrate how it is normally used, and correct for critical errors (Table 2).

For DPI selection, consider whether more than one type of DPI is needed and ensure that patients have the required PIF of $>30 \mathrm{~L} /$ minute. Small PIF-testing devices are available at no cost or minimal cost. Alternatively, patients who can perform adequate spirometry can usually generate a sufficient PIF to operate most DPIs. ${ }^{64}$

For pMDIs, observing use and repeated practice can improve the needed coordination of breathing with actuation. Use of a spacer can remove concerns about timing, but not the strength and dexterity required for actuation. Table 3 lists suitable inhaler device types based upon the patient's inhalation skills. ${ }^{65}$

\section{(3) How can I ensure that the correct inhaler technique will be taught to the patient?}

Training and monitoring patients in correct inhaler use can help improve pMDI, DPI, and SMI use. ${ }^{42,66}$ Several placebo devices are available for training patients to use inhalers correctly; $;{ }^{67}$ however, simply having training devices available is insufficient. Inhaler instruction, assessment, and monitoring should become an assigned and accountable clinical task, in the same way that assessing and recording smoking status has become a required vital sign. ${ }^{68}$ Assumptions that patients, families, or caregivers will understand how to use their inhaler device, correctly following instructions received from their pharmacist or by reading the package inserts, are unjustified. ${ }^{60}$

Inhaler technique should be assessed at each visit, and either individual or group learning can be used depending on feasibility. Combinations of devices should be avoided 
Table 3 Inhaler suitability based on patient breathing and coordination

\begin{tabular}{|c|c|c|c|}
\hline \multicolumn{2}{|c|}{ Good breath actuation and coordination } & \multicolumn{2}{|c|}{ Poor breath actuation and coordination } \\
\hline $\begin{array}{l}\text { Peak inspiratory } \\
\text { flow }>30 \mathrm{~L} / \text { minute }\end{array}$ & $\begin{array}{l}\text { Peak inspiratory } \\
\text { flow }<30 \mathrm{~L} / \text { minute }\end{array}$ & $\begin{array}{l}\text { Peak inspiratory } \\
\text { flow }>30 \mathrm{~L} / \text { minute }\end{array}$ & $\begin{array}{l}\text { Peak inspiratory } \\
\text { flow }<30 \mathrm{~L} / \text { minute }\end{array}$ \\
\hline Nebulizer & Nebulizer & Nebulizer & Nebulizer \\
\hline pMDI & pMDI & pMDI + spacer & pMDI + spacer \\
\hline DPI & DPI (HandiHaler) & DPI & DPI (HandiHaler) \\
\hline $\mathrm{SMI}^{\mathrm{a}}$ & $S M l^{a}$ & SMI ${ }^{a}$ & SMl ${ }^{\mathrm{a}}$ \\
\hline
\end{tabular}

Notes: aBecause of its slow-moving aerosol cloud, the SMI may be less error-prone even in patients with poor coordination, although this has not been specifically studied. Copyright (c) 200I, Elsevier Masson SAS. Adapted with permission from Voshaar T, App EM, Berdel D, et al. Recommendations for the choice of inhalatory systems for drug prescription Pneumologie. 200 I;55(I2):579-586. German. ${ }^{65}$

Abbreviations: DPI, dry powder inhaler; pMDI, pressurized metered-dose inhaler; SMI, soft mist inhaler.

whenever possible, but if both DPIs and pMDIs are used, visual cues can be used. For example, place stickers on the devices such as "slow breath in" (pMDI) or "quick breath in" (DPI).

\section{(4) Patient preferences and affordability}

a. Which devices are affordable/reimbursable for the patient?

Affordability may be the ultimate factor in patient preference. Health professionals need to know the cost implications when prescribing any drug and device. When substitutes are not clinically acceptable, alternative payment strategies and support are required. Social, public health, and pharmaceutical company services may be helpful.

\section{b. Does the patient have a device preference?}

The patient may have a preference for a particular device, based on familiarity or past experiences with specific inhalers. This may lead to better adherence and faster technique mastery, although whether this results in improved clinical outcome has never been proven. ${ }^{25}$

\section{c. Monitoring inhaler use and adherence}

COPD occurs later in life, when a patient's physical and cognitive abilities are likely to decline over time; therefore, not only must the appropriateness of the drug be assessed and reassessed but also the device. In many cases, the type of device used for inhaled medications must be modified to fit the patient's changing needs and abilities.

\section{Summary}

Sustained bronchodilator therapy for moderate to severe COPD (GOLD grades 2 and 3), has been shown to have clinical benefits on long-term symptom control and quality of life, with possible benefits on disease progression and longevity. ${ }^{2-6,8,57}$ The importance of correct inhaler device use in achieving optimum disease management in COPD cannot be overemphasized. Understanding the practical aspects of inhaler use, including device selection, correct inhalation techniques, and adherence is key to the early and successful management of patients with COPD in the primary care setting. ${ }^{69}$ Successful COPD management will be achieved by improving device selection based on individual patients' needs, together with patient education, training, high-quality physician-patient communication, and regular monitoring.

\section{Acknowledgments/disclosure}

Dr Yawn's employer has received consultation fees from Boehringer Ingelheim/Pfizer and research funding from Boehringer Ingelheim/Pfizer, Novartis, GlaxoSmithKline, and Merck for her work related to chronic respiratory diseases.

Dr Colice is a speaker/advisor/consultant for GlaxoSmithKline, Schering-Plough, Merck, Almirall, Skye, MedImmune, Asubio, Boehringer Ingelheim/Pfizer, and Dey.

Dr Hodder (deceased) had received consulting and speaking honoraria, and research funding from several pharmaceutical companies, including Boehringer Ingelheim, GlaxoSmithKline, AstraZeneca, Nycomed, and Novartis.

All authors meet the International Committee of Medical Journal Editors authorship criteria.

This article was developed on the basis of the authors' presentations and discussions at the "Implications of Inhalation Delivery Systems for COPD Therapies" advisory board held in New York, March 25-26, 2009. This meeting, the authors' participation, and manuscript preparation were supported by Boehringer Ingelheim Pharmaceuticals and Pfizer. Medical writing assistance was provided by Gill Sperrin, CMPP, CBiol, MSB, of Envision Scientific Solutions. The article reflects the concepts of the authors and is their sole responsibility. It was not reviewed by Boehringer Ingelheim Pharmaceuticals or Pfizer, except to ensure medical and safety accuracy.

\section{References}

1. Miniño AM, Xu J, Kochanek KD. Deaths: preliminary data for 2008. Natl Vital Stat Rep. 2010;59(2):1-71. 
2. Celli BR, Thomas NE, Anderson JA, et al. Effect of pharmacotherapy on rate of decline of lung function in chronic obstructive pulmonary disease: results from the TORCH study. Am J Respir Crit Care Med. 2008;178(4): 332-338.

3. Tashkin DP, Celli B, Senn S, et al. A 4-year trial of tiotropium in chronic obstructive pulmonary disease. N Engl J Med. 2008;359(15): 1543-1554.

4. Celli B, Decramer M, Kesten S, Liu D, Mehra S, Tashkin DP. Mortality in the 4-year trial of tiotropium (UPLIFT) in patients with chronic obstructive pulmonary disease. Am J Respir Crit Care Med. 2009;180(10):948-955.

5. Decramer M, Celli B, Kesten S, Lystig T, Mehra S, Tashkin DP. Effect of tiotropium on outcomes in patients with moderate chronic obstructive pulmonary disease (UPLIFT): a prespecified subgroup analysis of a randomised controlled trial. Lancet. 2009;374(9696): 1171-1178.

6. Suissa S, Ernst P, Vandemheen KL, Aaron SD. Methodological issues in therapeutic trials of COPD. Eur Respir J. 2008;31(5):927-933.

7. Karner C, Cates CJ. Combination inhaled steroid and long-acting beta(2)-agonist in addition to tiotropium versus tiotropium or combination alone for chronic obstructive pulmonary disease. Cochrane Database Syst Rev. 2011;3:CD008532.

8. Calverley PM, Anderson JA, Celli B, et al. Salmeterol and fluticasone propionate and survival in chronic obstructive pulmonary disease. N Engl J Med. 2007;356(8):775-789.

9. Bourbeau J, van der Palen J. Promoting effective self-management programmes to improve COPD. Eur Respir J. 2009;33(3): 461-463.

10. Koff PB, Jones RH, Cashman JM, Voelkel NF, Vandivier RW. Proactive integrated care improves quality of life in patients with COPD. Eur Respir J. 2009;33(5):1031-1038.

11. Troosters T, Gosselink R, Langer D, Decramer M. Pulmonary rehabilitation in chronic obstructive pulmonary disease. Respir Med COPD Update. 2007;3(2):57-64.

12. US Preventive Services Task Force. Screening for chronic obstructive pulmonary disease using spirometry: US Preventive Services Task Force recommendation statement. Ann Intern Med. 2008;148(7):529-534.

13. Lin K, Watkins B, Johnson T, Rodriguez JA, Barton MB. Screening for chronic obstructive pulmonary disease using spirometry: summary of the evidence for the US Preventive Services Task Force. Ann Intern Med. 2008;148(7):535-543.

14. Celli BR, MacNee W. Standards for the diagnosis and treatment of patients with COPD: a summary of the ATS/ERS position paper. Eur Respir J. 2004;23(6):932-946.

15. Global Initiative for Chronic Obstructive Lung Disease (GOLD). Global Strategy for the Diagnosis, Management and Prevention of Chronic Obstructive Pulmonary Disease. Revised December 2011. Available from: http://www.goldcopd.org. Accessed March 22, 2012.

16. Vincken W, Dekhuijzen PR, Barnes P; Admit Group. The ADMIT series - Issues in Inhalation Therapy. 4. How to choose inhaler devices for the treatment of COPD. Prim Care Respir J. 2009;19(1):10-20.

17. Dolovich MB, Ahrens RC, Hess DR, et al. Device selection and outcomes of aerosol therapy: evidence-based guidelines: American College of Chest Physicians/American College of Asthma, Allergy, and Immunology. Chest. 2005;127(1):335-371.

18. Melani AS, Bonavia M, Cilenti V, et al. Inhaler mishandling remains common in real life and is associated with reduced disease control. Respir Med. 2011;105(6):930-938.

19. Rootmensen GN, van Keimpema AR, Jansen HM, de Haan RJ. Predictors of incorrect inhalation technique in patients with asthma or COPD: a study using a validated videotaped scoring method. J Aerosol Med Pulm Drug Deliv. 2010;23(5):323-328.

20. Nikander K. Challenges and opportunities in respiratory drug delivery devices. Expert Opin Drug Deliv. 2010;7(11):1235-1238.

21. Fromer L, Goodwin E, Walsh J. Customizing inhaled therapy to meet the needs of COPD patients. Postgrad Med. 2010;122(2):83-93.
22. Geller DE. Comparing clinical features of the nebulizer, metereddose inhaler, and dry powder inhaler. Respir Care. 2005;50(10): 1313-1322.

23. Chapman KR, Voshaar TH, Virchow JC. Inhaler choice in primary practice. Eur Respir Rev. 2005;14(96):117-122.

24. Bourbeau J, Bartlett SJ. Patient adherence in COPD. Thorax. 2008;63(9):831-838.

25. Hodder R. Design and interpretation of device preference trials: marketing tools or scientific instruments? In: Dalby RN BP, Peart J, Suman JD, Farr SJ, editors. Respiratory Drug Delivery X. Vol 1. River Grove: Illinois Davis Healthcare; 2006:19-36.

26. Anderson PJ. History of aerosol therapy: liquid nebulization to MDIs to DPIs. Respir Care. 2005;50(9):1139-1150.

27. Chapman KR, Love L, Brubaker H. A comparison of breath-actuated and conventional metered-dose inhaler inhalation techniques in elderly subjects. Chest. 1993;104(5):1332-1337.

28. Anhøj J, Bisgaard H, Lipworth BJ. Effect of electrostatic charge in plastic spacers on the lung delivery of HFA-salbutamol in children. $\mathrm{Br}$ J Clin Pharmacol. 1999;47(3):333-336.

29. Chuffart AA, Sennhauser FH, Wildhaber JH. Factors affecting the efficiency of aerosol therapy with pressurised metered-dose inhalers through plastic spacers. Swiss Med Wkly. 2001;131(1-2):14-18.

30. Wieshammer S, Dreyhaupt J. Dry powder inhalers: which factors determine the frequency of handling errors? Respiration. 2008;75(1):18-25.

31. Gooneratne NS, Patel NP, Corcoran A. Chronic obstructive pulmonary disease diagnosis and management in older adults. J Am Geriatr Soc. 2010;58(6):1153-1162.

32. van der Palen J, Klein JJ, van Herwaarden CL, Zielhuis GA, Seydel ER. Multiple inhalers confuse asthma patients. Eur Respir J. 1999;14(5):1034-1037.

33. Kunkel G, Magnussen H, Bergmann K, et al. Respimat (a new soft mist inhaler) delivering fenoterol plus ipratropium bromide provides equivalent bronchodilation at half the cumulative dose compared with a conventional metered dose inhaler in asthmatic patients. Respiration. 2000;67(3):306-314.

34. Boehringer Ingelheim. Combivent Respimat inhalation spray. Available from: http://www.combivent.com/respimat.html. Accessed March 22 2012 .

35. Molimard M, Raherison C, Lignot S, Depont F, Abouelfath A, Moore N. Assessment of handling of inhaler devices in real life: an observational study in 3811 patients in primary care. JAerosol Med Pulm Drug Deliv. 2003;16(3):249-254.

36. Fink JB, Rubin BK. Problems with inhaler use: a call for improved clinician and patient education. Respir Care. 2005;50(10):1360-1374; discussion 1374-1365.

37. McFadden ER Jr. Improper patient techniques with metered dose inhalers: clinical consequences and solutions to misuse. J Allergy Clin Immunol. 1995;96(2):278-283.

38. Lavorini F, Magnan A, Dubus JC, et al. Effect of incorrect use of dry powder inhalers on management of patients with asthma and COPD. Respir Med. 2008;102(4):593-604.

39. Schulte M, Osseiran K, Betz R, et al. Handling of and preferences for available dry powder inhaler systems by patients with asthma and COPD. J Aerosol Med Pulm Drug Deliv. 2008;21(4):321-328.

40. Thomas M, Price D, Chrystyn H, Lloyd A, Williams AE, von Ziegenweidt J. Inhaled corticosteroids for asthma: impact of practice level device switching on asthma control. BMC Pulm Med. 2009;9:1.

41. McDonald VM, Higgins I, Simpson JL, Gibson PG. The importance of clinical management problems in older people with COPD and asthma: do patients and physicians agree? Prim Care Respir J. 2011;20(4):389-395.

42. Melani AS, Bracci LS, Rossi M. Reduced peak inspiratory effort through the Diskus ${ }^{\circledR}$ and the Turbuhaler ${ }^{\circledR}$ due to mishandling is common in clinical practice. Clin Drug Investig. 2005;25(8):543-549.

43. Jarvis S, Ind PW, Shiner RJ. Inhaled therapy in elderly COPD patients; time for re-evaluation? Age Ageing. 2007;36(2):213-218. 
44. Yohannes AM, Baldwin RC, Connolly MJ. Prevalence of sub-threshold depression in elderly patients with chronic obstructive pulmonary disease. Int J Geriatr Psychiatry. 2003;18(5):412-416.

45. Maurer J, Rebbapragada V, Borson S, et al. Anxiety and depression in COPD: current understanding, unanswered questions, and research needs. Chest. 2008;134(Suppl 4):43S-56S.

46. Gelberg J, McIvor RA. Overcoming gaps in the management of chronic obstructive pulmonary disease in older patients: new insights. Drugs Aging. 2010;27(5):367-375.

47. Georges CA, Bolton LB, Bennett C. Functional health literacy: an issue in African-American and other ethnic and racial communities. J Natl Black Nurses Assoc. 2004;15(1):1-4.

48. Restrepo RD, Alvarez MT, Wittnebel LD, et al. Medication adherence issues in patients treated for COPD. Int J Chron Obstruct Pulmon Dis. 2008;3(3):371-384.

49. Kuhl K, Schürmann W, Rief W. Mental disorders and quality of life in COPD patients and their spouses. Int J Chron Obstruct Pulmon Dis. 2008;3(4):727-736.

50. Lareau SC, Yawn BP. Improving adherence with inhaler therapy in COPD. Int J Chron Obstruct Pulmon Dis. 2010;5:401-406.

51. Jung E, Pickard AS, Salmon JW, Bartle B, Lee TA. Medication adherence and persistence in the last year of life in COPD patients. Respir Med. 2009;103(4):525-534.

52. Sestini P, Cappiello V, Aliani M, et al. Prescription bias and factors associated with improper use of inhalers. J Aerosol Med Pulm Drug Deliv. 2006;19(2):127-136.

53. Virchow JC, Crompton GK, Dal Negro R, et al. Importance of inhaler devices in the management of airway disease. Respir Med. 2008;102(1):10-19.

54. Gustafsson P, Taylor A, Zanen P, Chrystyn H. Can patients use all dry powder inhalers equally well? Int J Clin Pract Suppl. 2005;(149): 13-18.

55. Madoc-Sutton H, Hardy A, Fletcher M, Walker S. Assessment of key influences on asthma inhaler device selection. Nurs Stand. 2009;23(24):35-41.

56. Rau JL. Practical problems with aerosol therapy in COPD. Respir Care. 2006;51(2):158-172.
57. Vestbo J, Anderson JA, Calverley PM, et al. Adherence to inhaled therapy, mortality and hospital admission in COPD. Thorax. 2009;64(11):939-943.

58. Yawn BP, Wollan PC. Knowledge and attitudes of family physicians coming to COPD continuing medical education. Int J Chron Obstruct Pulmon Dis. 2008;3(2):311-317.

59. Belfer MH. Office management of COPD in primary care: a 2009 clinical update. Postgrad Med. 2009;121(4):82-90.

60. Broeders ME, Sanchis J, Levy ML, Crompton GK, Dekhuijzen PN. The ADMIT series - issues in inhalation therapy. 2. Improving technique and clinical effectiveness. Prim Care Respir J. 2009;18(2):76-82.

61. Tarn DM, Heritage J, Paterniti DA, Hays RD, Kravitz RL, Wenger NS. Physician communication when prescribing new medications. Arch Intern Med. 2006;166(17):1855-1862.

62. Allen SC, Prior A. What determines whether an elderly patient can use a metered dose inhaler correctly? Br J Dis Chest. 1986;80(1):45-49.

63. Wilson DS, Gillion MS, Rees PJ. Use of dry powder inhalers in COPD. Int J Clin Pract. 2007;61(12):2005-2008.

64. Malmberg LP, Rytila P, Happonen P, Haahtela T. Inspiratory flows through dry powder inhaler in chronic obstructive pulmonary disease: age and gender rather than severity matters. Int J Chron Obstruct Pulmon Dis. 2010;5:257-262.

65. Voshaar T, App EM, Berdel D, et al. Recommendations for the choice of inhalatory systems for drug prescription. Pneumologie. 2001;55(12):579-586. German.

66. Al-Showair RA, Tarsin WY, Assi KH, Pearson SB, Chrystyn H. Can all patients with COPD use the correct inhalation flow with all inhalers and does training help? Respir Med. 2007;101(11):2395-2401.

67. Lavorini F, Levy ML, Corrigan C, Crompton G. The ADMIT series - issues in inhalation therapy. 6. Training tools for inhalation devices. Prim Care Respir J. 2010;19(4):335-341.

68. Melani AS. Inhalatory therapy training: a priority challenge for the physician. Acta Biomed. 2007;78(3):233-245.

69. Yawn BP. Optimizing chronic obstructive pulmonary disease management in primary care. South Med J. 2011;104(2):121-127.
International Journal of COPD

\section{Publish your work in this journal}

The International Journal of COPD is an international, peer-reviewed journal of therapeutics and pharmacology focusing on concise rapid reporting of clinical studies and reviews in COPD. Special focus is given to the pathophysiological processes underlying the disease, intervention programs, patient focused education, and self management protocols.

\section{Dovepress}

This journal is indexed on PubMed Central, MedLine and CAS. The manuscript management system is completely online and includes a very quick and fair peer-review system, which is all easy to use. Visit http://www.dovepress.com/testimonials.php to read real quotes from published authors. 